\title{
GLOBAL VALUES IN THE CONTEXT OF CIVILIZATIONAL DIALOGUE
}

\author{
Ivan Aleshkovski \\ Lomonosov Moscow State University
}

Alexander Gasprishvili

Lomonosov Moscow State University

Natalia Smakotina

Lomonosov Moscow State University

\begin{abstract}
The aim of the article is to reveal common axiological attitudes of various groups of experts in Russia and abroad toward civilizational dialogue and cooperation between different countries and peoples. The paper demonstrates how the representatives of expert communities from different countries describe the features and limits of global values. The authors emphasize the interdisciplinary nature of the subject and the need for a comprehensive approach to its study in conjunction with various branches of social sciences (philosophy, psychology, sociology and political science) in order to develop common scientific principles for solving urgent problems common to all humanity.
\end{abstract}

Keywords: globalization, global values, identity, civilizational dialogue, global civilization.

\section{Introduction}

Post-industrial development of civilization in the twenty-first century has complicated the world, made the arisen realities vulnerable and presented humanity with the challenge of fundamental value diversity. In the time of increasingly rapid modern society transformation, ща large-scale changes embracing each government, and growing contradictions in value systems of different civilizations and nations, one should study the global universal values and beliefs that shape the basis for a productive dialogue between peoples and states.

The sustainable development of the world presupposes the existence of an optimal value consensus related to a constructive dialogue that is based on global universal values with the preservation and development of national cultures and historically established identities. Social values are necessary not only for a personal development but also for uniting people from different social groups. In this connection, the issue of finding universal values for countries with different social and economic situation and culture is of current importance.

The global perspective of the study requires an interdisciplinary approach. One should rely on the achievements of different social sciences, each examining its own aspect of values. Philosophy explores the worldview aspect of values. For philosophy,

Journal of Globalization Studies, Vol. 11 No. 1, May 2020 73-85

DOI: $10.30884 / j o g s / 2020.01 .05$ 
values are common subjective images that have a human dimension. Sociology connects values with social norms of human life organization. Political scientists talk about political values that motivate, guide and justify actions of political actors, reflect the state, needs and prospects for development of society, its main social groups. Without reliance upon the development of all these sciences, it would be impossible to develop a conceptual approach to the global universal values of contemporary humanity.

\section{Methodology}

We proceeded from the methodology where the development of a scientific basis for global values was caused by a number of conceptual differences among the researchers. There is a contradiction between an object interpretation of values (where any object capable of satisfying human needs is regarded as a value), a subject-object interpretation of values (where a value appears as a subject-object relation of the object's significance for the subject) and a subject interpretation (where values appear as people's motivational preferences linked to the ultimate goal of life). A contradiction in the understanding of truth-value links is not resolved. Some argue that values can be true or false. This point of view is opposed by David Hume (2005) and Immanuel Kant (1996) who contended that an epistemological verification of values was impossible. Values can be generally valid and even compulsory for all, but they cannot be true or false, since what is due in this world does not reduce itself to what is existing and is not inferred thereof (Putnam 2002).

Modern humanity is affected by an unlimited flow of information, which it is unable to absorb. We continue to interact with it to the extent that the matrix of our individual development allows us. The global omnipresence of 'values' that turned from a philosophical concept into an everyday one has resulted in the fact that the very use of the term 'value' has lost any definite meaning. While the science of values (axiology) points to a deep crisis due to many unsolved theoretical problems, from the early $1970 \mathrm{~s}$ to the present day there has been a boom in applied research in a wide range of axiological and near-axiological studies with monographs, collaborative works and articles being written, national and international symposiums being held, and special periodicals published and full-scale institutes set up to study them (Shokhin 2006).

The researchers who are professionally engaged in axiology sound the alarm, because these pragmatically oriented studies and events lower the level of theorizing and lead to methodological chaos and depreciation of the very concept of 'values' in modern culture. Leaving the concept of 'value' to denote the deepest layer of the personality's intentional structure, or, let us put it simply, for personal preferences and priorities, they propose to use a more 'sociologically loaded' word - priorities - to denote what is now understood as economic, environmental, political, sociocultural, etc. values. At the same time, they rightly believe that most sociologists are unlikely to abandon the broadened word usage which has already become habitual.

It is worth noting that the aforementioned boom in axiological studies coincided with the onset of the globalization. On the one hand, the processes of unification of 'a world without borders' has started but, on the other hand, the processes of localization, regionalization, multiculturalism and religious fundamentalism were getting underway. 
The discussions on the concept of globalization have been going on since the 1980s. The problem of globalization is that it is impossible to single out something and say: that is what globalization is all about, because it implies not one, but many processes, some of which can be polar opposites (Heywood 2012: 173). In this regard, the debate around globalization goes in many directions. The proponents of globalization believe that it brings prosperity and opportunities for all inhabitants of the earth; its opponents, however, argue that it is fraught with new forms of exploitation, inequality, and new forms of poverty and injustice. But can we speak today not about economic or political aspects of globalization, but about another globalism that would suit everyone - about the 'globalism of humanitarian values?' In other words, are there such humanitarian values that are global in nature and are shared by people throughout the world? With a certain degree of conventionality, let us pose the question this way: if globalization either directs humanity towards a 'single global society', or necessitates a dialog between different civilizations can we speak about global universal values today?

Global universal values represent a new concept. Still, they can be found in the history of ideas under a different name, viz. universal values, or universal human values. As for universal human values, there are two directly opposite views, two approaches in philosophy.

These two viewpoints have existed since ancient times, but today, thanks to globalization, they have become more topical and timely than ever in the history of humankind. The first one, based on the idea of the equality of all people by nature, obviously originates from the Athenian Stoics, who equalized all people in the face of the universal law (Stepanov 1995). Today, this stance is actively defended and supported by liberals, who are convinced that all people, regardless of race, religion, social status and ethnic background, are morally equal. Christianity is based on this idea. The Dalai Lama XIV calls on modern humanity to disseminate universal values (Dalai Lama and Ekman 2008). At the other extreme, the idea of natural quality and, accordingly, the universal values themselves are interpreted as a limited and historically obsolete idea, a tribute to the mythical form of thinking (Scheler 1999; Malinkin 1999). The first standpoint is identified by its opponents as idealism and utopianism. Those opposing the latter standpoint share Albert Einstein's belief that 'nationalism is an infantile disease. It is the measles of mankind' (Viereck 1929).

Similar contradictions can be found in political science. Quite a number of political scientists doubt the existence of global universal values. In their view, there are only national interests that politicians tend to present as global values. They argue that there are only national interests which politicians are inclined to present as global values or that values can only exist at the level of small communities (Falk et al. 1982). Some authors believe that 'globalization can bring people together only to understand how different they really are' (Halliday 2000). At the same time, there are theories that disregard the fundamental differences between national and confessional cultures; their supporters believe that there are values which are 'universally applicable and shared by all people' (Koskenniemi 2005). Besides, there is no generally acknowledged typology of human values. 
If one proceeds from the idea that global processes are those occurring on planet Earth, spreading over its entire territory and displaying a certain 'global planetary integrity', then one can agree with the proponents of the existence of certain values that are global, universal and recognized by all peoples of the planet.

It should be borne in mind, however, that any value must be considered in terms of two parameters, that is, their formal names and the interpretation of their content. Thus, the concept of 'universal values' may contain a certain paradox. In terms of formal names, there can be values that are spoken about and handled by representatives of all countries and peoples, representatives of the political elite, scientific communities and ordinary citizens, for example peace, security, pursuit of happiness, justice, etc. Nevertheless, in terms of interpretation, these values may not turn out universal, because representatives of various social strata and groups can put their own distinctive content.

In 2018, the Lomonosov Moscow State University implemented the interdisciplinary project 'Global Values: a Scientific Basis for the Existence of Global Values as a Foundation of Contemporary Society Development'. Within this project we proceeded from the notion of 'globalization' presupposing a level, on which the influence of different values on the life of world community, including religious, economic, social and political systems of the global world. Special aspects in the interpretation of global universal values represent a fundamentally new task that has not yet been sufficiently elaborated. At this stage, we consider it possible to analyze the interpretations of values in various political cultures in terms of their semantics.

As a result of this approach, the most frequently mentioned values in the analyzed papers (Foreign Policy Concept of the Russian Federation 2016; Shared Vision 2016; The Sustainable Development 2017; The Advancing Freedom 2017; Xi Jinping 2017) that could be treated as global and universal ones were singled out. We united those that were close in their meaning. Then, we made a list of nine separate values and used this list in the development of research tools.

The list includes the following:

- Education;

- Equality;

- Freedom;

- Humanism;

- Justice;

- Patriotism;

- Progress;

- Responsibility;

- Security.

At the preliminary stage the following expert groups were singled out:

- representatives of 'Global Studies' International Consortium;

- experts in the field of international cooperation from Western Europe and the USA who do not belong the "Global Studies" Consortium;

- Russian scholars in social studies specializing in the field of global research;

- experts from the BRICS countries (the participants of the Association of BRICS research and educational centers). 
The first group of experts represented the 'Global Studies' International Consortium, an international network of graduate programs in global studies. One of its purposes is to promote and facilitate graduate teaching programs in Global Studies and to foster cooperation among them. The consortium includes 37 universities from around the world, including universities from the United States, Russia, and some European and Asian countries. The invitations to take part in the survey and research questionnaires were sent to the representatives of all 37 programs in Global Studies. The responses were received from 29 people. Twenty seven questionnaires were completely filled out and contained relevant answers.

To form a group of experts in the field of international cooperation from Western Europe and the USA who do not enter the 'Global Studies' Consortium, we used a database created at the Faculty of Global Studies of Lomonosov Moscow State University, which contains data on the publications of 900 authors from around the world. At the first stage of formation of the group of experts scholars from the universities in the USA and Western Europe were selected on the basis of a list of publications. At the second stage scholars representing Global Studies programs from the 'Global Studies' International Consortium were excluded from the list. Then publications with one author were selected. Then, in articles with multiple authors, if the authors were not listed alphabetically, the first author was selected, if alphabetically - the author was selected randomly. As a result, a list of 93 authors was made. Among the selected 93 we managed to find e-mails of 67 authors. The invitations to take part in the survey and research-questionnaires were sent to all of them. Finally, we received responses from 38 scholars. Among them 11 filled out questionnaires completely and gave relevant answers to the survey questions.

The list of Russian experts was formed in a similar way. The publications of Russian researchers were selected from the database of the Faculty of Global Processes. Then articles with one author were selected from the received list. In multi-author articles, if authors were not listed alphabetically, the first author was selected. In case the authors were listed alphabetically, the author was selected randomly. As a result, a list of 51 authors was formed. We managed to determine e-mails of 43 scholars. They were sent offers to participate in the survey and questionnaires. The answer was received from 29 people. Eleven questionnaires were filled out completely and contained relevant answers.

The list of the experts from BRICS countries was formed using the database of the participants of the Association of BRICS Research and Educational Centers. The invitation to participate in the study and questionnaires were sent by e-mail to 42 representatives of research and educational centers of Brazil, India, China and South Africa. Responses were received from 24 scholars. Thirteen responses meet the requirements of our research.

All experts were interviewed using online semi-formalized questionnaire, which combines closed- and open-ended questions. 


\section{Results}

We sought to understand whether the values on the list matched the experts' views on the values deemed to be global and universal ones. In other words, we were interested to know whether there was a convergence of views in the global expert community on what constitutes global and universal values.

As is seen from the results, the majority of values on the list can be considered as global and universal. However, the opinions of different expert groups do not necessarily coincide. Due to the specific characteristics of the expert survey, applying statistical methods for data analysis was not applicable. Therefore, we had to refrain from comparing numerical indices because of the limited number of people in expert groups. In applied research, we can only outline the trends.

Practically all expert groups regard justice, education, security, humanism and progress as global universal values. The Russian experts seem less inclined to think of justice as a global universal value than others (see Fig. 1).

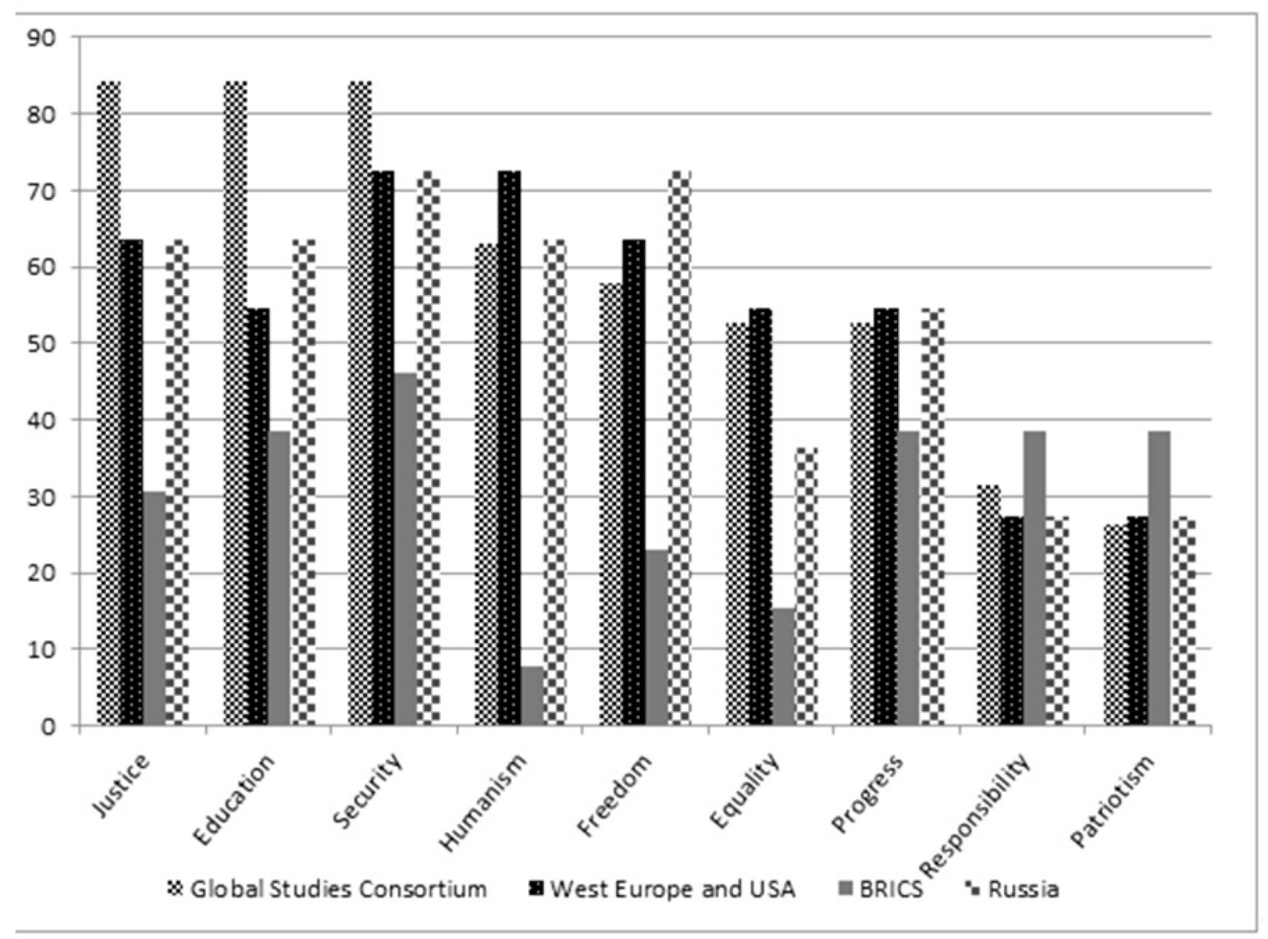

Fig. 1. Global universal values from the experts' point of view

The experts from the BRICS countries stand out from other expert groups as many of them do not consider either of the values on the list as global and universal ones. Only the security issue is considered global by almost half of the respondents in this group.

To explain the reasons for such a distribution of opinions it is necessary to have a larger interdisciplinary research and more complex research tools. However, the survey results have definitely shown that there is an agreement in expert community not 
only about the existence of such a phenomenon as global universal values, but also about the accordance in the global expert community on which values should be treated as global universal ones.

Another task was to compare specific global values from the point of view of their importance for different expert groups. We then compared the values against their primary importance for humanity, leaving aside their belonging to global universal ones. The experts were asked to point out three most significant values from those they had singled out as global universal ones (see Fig. 2).

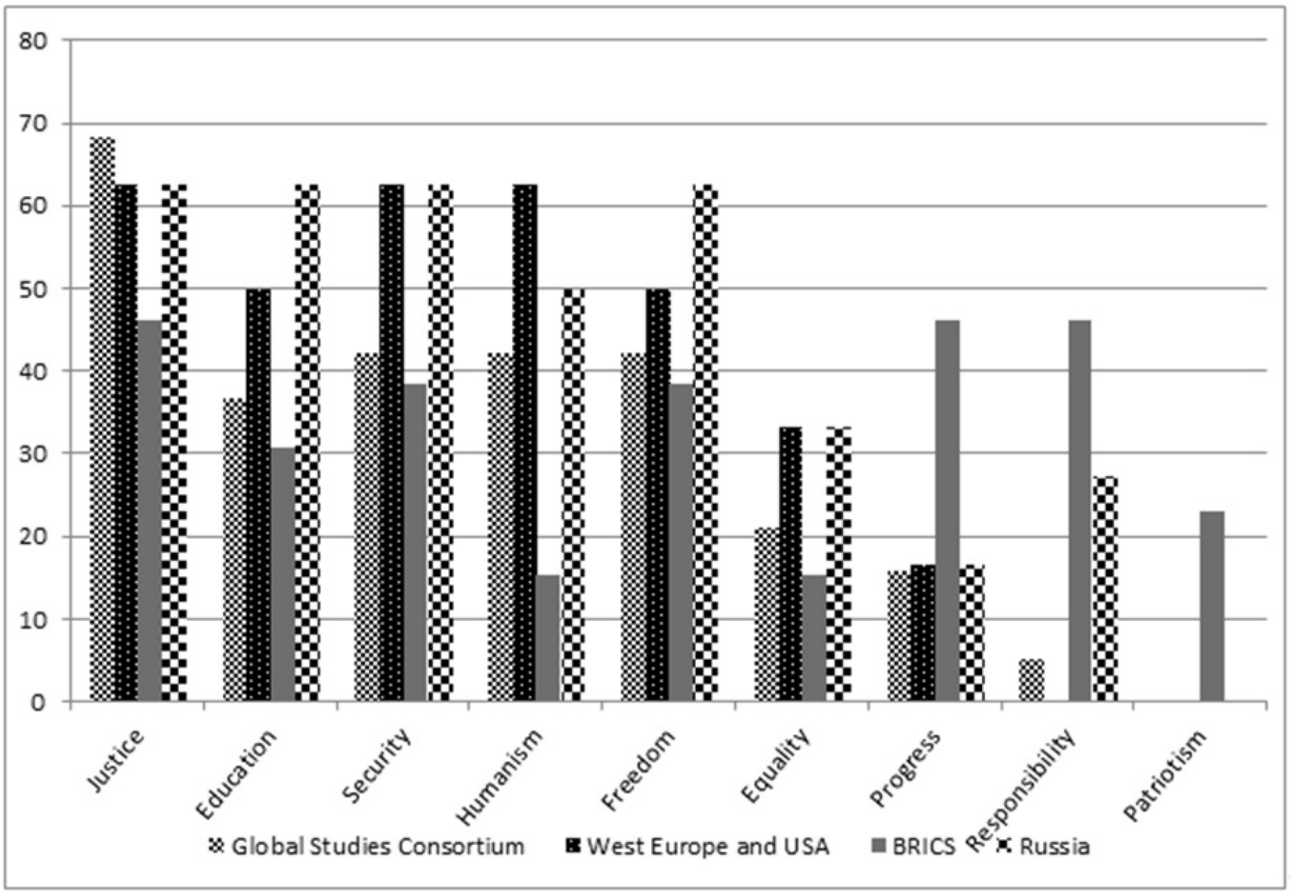

Fig. 2. The most significant global values

As is seen from the survey, the most significant global values are justice, education, security and freedom.

One can identify some tendencies in the assessment by different expert groups:

- for the representatives of International Global Studies Consortium, that is 'professional globalists' - justice, freedom and security are the most valuable;

- the experts in the field of international cooperation from Western Europe and the USA, who are not part of the Global Studies Consortium, and the Russian experts both appreciated justice and security. They also coincide in assessing equality. There are certain differences in education and freedom assessment - the Russian experts tend to estimate these values as the most important ones.

As in the case with choosing global universal values, the experts from the BRICS countries differ from the others. They give priority to justice, progress and responsibility.

The issue of the content of global universal values seen from the perspective of different expert groups was one of the most essential ones. To this end, open questions 
were included in research tools that allowed the respondents to formulate their answers on their own, and thus gave the researchers more detailed information about their opinions and ideas. When answering open questions, the experts had to define what meaning they put in those values they called global.

Before giving an outline of this research, one should note that the definitions of values given by the respondents do not depend on their culture, civilization, country, social group, etc.

\section{Security}

Security is defined as protection and preservation of people's life in accordance with norms adopted in society; security of vital interests of person, society, country, humanity at large from inner and outer threats; confidence in the future, being safe and calm for oneself and for one's relatives; conditions when a person is secured from encroachments of all kinds on his/her life, personality and health all over the world; preservation of human life, health and rights; possibility to live and be sure about one's future and the future of one's children. Security is the basis of life in our unstable world.

Justice

Despite the fact that many Russian experts attributed justice to the three most important values, they did not define it for some reason. By contrast, foreign experts have defined it quite thoroughly. In general, their ideas correspond to Aristotle's concept about common and private justice that is still relevant. Justice is a common moral component of all relations among people, nations and states; it presupposes living rightly and helping each other.

Some definitions of justice fit the liberal-democratic social theories: justice is when everyone has equal rights regarding general freedoms; justice presupposes respect to each other and to the interests of other people, nations and states.

There are also definitions of justice coming from the sphere of morals: justice means confidence in the fact that a man lives for some purpose, that good deeds are to be estimated rightly while vices and evil deeds are to be punished; justice is the interconnection of deeds and punishment.

\section{Humanism}

No wonder that humanism is among the main global universal values. It embraces respect to life and love for each person, as well as for all humankind. Experts gave the following definitions: humanism is the acknowledgment of the most important issues on the Earth and in any country - man's life and dignity; care for life, health and inner world; respect and love for oneself and for other people; admission of the fact that human life is priceless, and that the weak should be treated with special care; we should treat others not as the citizens of different countries but as ourselves.

\section{Freedom}

There is a common opinion that freedom is understood differently in diverse cultures, in particular, it differs in Russian and Western cultures. However, there are not such differences at the expert community level. The definitions of freedom given by the experts can be divided into three groups: 
1) Freedom is a right by nature for everyone despite his/her origins as it belongs to him/her because he/she is a human;

2) Freedom is the most important human right to participate in social and political life of his or her country;

3) Freedom is the possibility of self-developing without restricting one's talents by someone's will.

Equality

Equality is a crucial democratic principle. Experts have specified it as a political equality, first of all in terms of equality before the law, when every citizen is equal before the law irrespective of nationality, race, religious and political beliefs, etc.; when there is an equal responsibility of everyone to abide by the law; when there are no privileges; and when people have an equal right to participate in politics.

\section{Education}

Education as a value has been broadly discussed by experts. This may be explained by the fact that the majority of experts being university teachers or scientists associate themselves with the sphere of science and higher education. Education is generally understood as an introduction to a universally accepted moral, social and religious reference points; it is the acquisition of skills necessary for a conscious and productive participation in social life of one's country and the whole world community.

\section{Progress}

Progress is quite frequently attributed to global universal values. Perhaps, it is connected with the fact that many people are disappointed by scientific and technical opportunities to enable happy future, as well as they are aware of negative effects that modern science and technology may produce on nature. Probably it is predetermined by modern prejudices against the mere notion of progress. The idea of progress treated as a global universal value is mostly characteristic of the BRICS countries. For those experts who placed progress among the main global universal values, progress had the following meaning: it is the process of people's striving for a better future, freedom and justice; it is the development of science and technology that could guarantee a comfortable existence and the opportunity of developing person's individuality; it is the exploration of the world; it is the overcoming of irregularities in economic development of different countries and regions.

\section{Patriotism}

By placing patriotism among main global universal values, the experts define it as love for one's country, nation, respect for the country's traditions; manifestations of patriotism are aimed at strengthening and developing of the country. Patriotism is a significant value, common for all humankind, lying in the basis of an aspiration for developing and strengthening one's state not to the detriment of other countries.

These results can become a foundation for the matrix of global values in order to increase mutual understanding among representatives of different social groups in various countries. They can also be used to forecast and minimize possible risks of social 
practices connected to the difference in interpretation of value meaning. For that it is necessary to identify why experts prioritize these or those global universal values. Their argumentation could be used in forming various analytical and informational materials developed for a purposeful shaping of value unity and social solidarity based on perception of meaningful national and global values. This could guarantee social agreements and solidarity both within the country and at the international level.

\section{Security}

The experts who considered this particular value to be the most important gave an idea of its justification: 'Security unites us all. Everyone needs it. It is possible to build future only in a secure world.' 'We need security to give people the possibility to live and be sure of their future.' 'Security saves life.' 'People need to feel secure, to be sure of it as it gives them freedom.' 'A person can plan and build his or her life only in a secure society.'

\section{Justice}

There are three general ideas behind placing justice among global universal values:

1) injustice - the source of tensions and conflicts, and as a result-justice is the act of overcoming irregularities in the distribution of resources and wealth that provoke conflicts; lack of justice is a source of tensions and conflicts; justice helps to protect life by redistributing resources in favor of the weak;

2) belief in justice is the resource of human and humankind development - if there is no belief in justice in the world, or at least in one's milieu, then the meaning of life is lost; belief in justice helps to confidently face the future; it is the basis of a person's harmonious development;

3) justice is the value that demonstrates that every action towards other people, other states should be treated from the moral point of view; we should understand that any action towards others is fraught with their reaction towards us. Everyone should understand it, and only then it would become possible to hope that there would be harmonious relationship between countries and nations.

\section{Progress}

The experts who chose progress as the main value used the same argumentation as is the case with 'justice followers' who spoke about the redistribution of resources and wealth: thanks to progress the imbalances in the economic development of different countries and regions must be overcome: a man would get the possibility to satisfy his/her needs and develop his/her talents irrespective of the place of living; progress would help humanity to become a single community, thus eliminating intergovernmental conflicts and wars.

\section{Education}

The arguments in favor of education as a basic value were few and rather concise: $e d u$ cation is the means of human development and formation of an individual as a person and a citizen; it is the most important factor of social progress; a source of human and societal development. 


\section{Humanism}

All that surrounds us is meaningful as long as we, people, exist. Without love for people, for a particular person, without humanitarian policy, humans would have failed to survive not to speak of further development; humans would not be able to preserve fundamental human qualities - these are the main arguments of experts who named humanism the most significant global universal value: 'We are born humans. Unless we show our human characteristics and see them in others, there would be no human society, we could not find a common language and cooperate neither at the personal and group level nor at the governmental and intergovernmental level.' 'It is impossible to build a modern society without considering the subject - human. Humanism must be the basis of each politics both domestic and foreign.' "Humanism lets people be born, survive, develop and please the Creator.' 'Human life is the most precious value. Without love for humans and for a human being any group or government are meaningless.'

\section{Freedom}

Contemporary social sciences treat freedom as the highest spiritual value, as a fundamental human quality that defines a human being as a person. Perhaps, that is why some experts consider freedom as of the main global universal value: only free people can take a conscious participation in building a safe and just world order; freedom gives people an opportunity to manifest their best qualities.

\section{Patriotism}

The reasons for placing patriotism among the main global values are the following: love for one's country and nation is the most important factor of understanding and respect of other countries and nations; patriotism is a natural feeling of every sensible man; it is typical of people to be proud of their country and aspire for spreading its achievements around the world.

\section{Conclusions}

To sum up, one can draw the following three conclusions:

- Modern people really have the idea of the existence of a number of universal global values. These values allow people of different countries, cultures and civilizations to avoid conflicts and wars, to save life on Earth on the basis of mutual assistance and respect for human beings and protect him from dangers and challenges of the modern world;

- Even though the respondents named different values as global universal ones, their interpretation had a certain obsession with the context: progress is determined through freedom; security is connected with solidarity, etc. Therefore, one could speak of a whole set of value ideas, which define the integrity of the modern global worldview;

- There is no contradiction in interpretations of different experts. Although the respondents represent different states and cultures, they give certain values a common content.

Therefore, the problem of global universal values and their perception by different groups are of vital importance for civilizational dialogue and world sustainable development. 
The authors realize that the methodology of selecting experts applied in the study is certainly not irreproachable. It is also our view that the online survey method is far from the best method of studying the opinions of experts. We consider this study as the initial stage of a more detailed analysis of the problem, where more sophisticated methods of selecting experts and collecting data, such as in-depth interviews and group discussions, will be used. However, we believe that the results of this study, even with the account of the current level of analysis, may be of interest to scholars engaged in global studies and axiology, as well as to all those interested in global and value issues. We also hope that the results of the study will become the subject of scientific discussion and allow us to improve the methodology of our further study and its research tools.

\section{Acknowledgement}

We would like to thank the Russian Foundation for Basic Research (RFBR) for supporting our survey (Grant No. 19-014-00001). We express our gratitude to our international colleagues especially to the members of International Consortiums 'Global studies' for their participation in the survey and in the discussion of its outcomes.

\section{REFERENCES}

Ekman, P. (Ed.) 2008. Emotional Awareness: Overcoming the Obstacles to Psychological Balance and Compassion: A Conversation between the Dalai Lama and Paul Ekman, Ph.D. New York: Times Books/Henry Holt and Co.

Falk, R., Kim, S. S., and Mendlovitz, S. H. 1982. Toward a Just World Order. Boulder: Westview Press, Michigan University.

Halliday, F. 2000. Global Governance: Prospects and Problems. Citizenship Studies 4 (1): 19-33.

Heywood, A. 2012. Politics. $2^{\text {nd }}$ Edition. New York: Palgrave Macmillan.

Hume, D. 2000. A Treatise of Human Nature. Oxford University Press; Dover Publications.

Kant, I. 1999. Critique of Pure Reason. The Cambridge Edition of the Works of Immanuel Kant. Translated and edited by Guyer, P. and Allen, W. Wood. Cambridge University Press.

Koskenniemi, M. 2005. International Law in Europe: Between Tradition and Renewal. The European Journal of International Law 16 (1): 113-124.

Malinkin, A. N. 1999. The Concept of Patriotism: Essay on the Sociology of Knowledge. Sotsiologhitcheski zhurnal 1-2: 87-117. Original in Russian (Малинкин, А. Н. Понятие патриотизма: эссе по социологии знания. Социиологческий журнал 1-2: 87-117).

Putnam, H. H. 2002. The Collapse of the Fact/Value Dichotomy and Other Essays. Cambridge, MA: Harvard University Press.

Scheler, M. 1999. Resentment in the Structure of Morals. St. Petersburg: Nauka. Original in Russian (Шелер, М. Ресентимент в структуре моралей. СПб: Наука).

Shokhin, V. K. 2006. Philosophy of Values and Early Axiological Thought. Moscow: RUDN Press. Original in Russian (Шохин В. К. Философия цеенностей и ранняя аксиологическая мысль. М.: РУДН). 
Shared Vision, Common Action: A Stronger Europe. A Global Strategy for the European Union's Foreign and Security Policy, June 2016. Accessed: 02.01.2019. URL: http://eeas.europa.eu/archives/docs/top_stories/pdf/eugs_review_web.pdf.

Stepanova, A. S. 1995. The Philosophy of the Ancient Stoa. St. Petersburg: Alethea. Original in Russian (Степанова, А. С. Философия Древней Стои. Санкт-Петербург: Алетейя).

Foreign Policy Concept of the Russian Federation (approved by President of the Russian Federation Vladimir Putin on November 30, 2016. Retrieved January 02, 2019, from the official website of The Ministry of Foreign Affairs of the Russian Federation: URL: http://www.mid.ru/foreign_policy/news/-/asset_publisher/cKNonkJE02Bw/content/id/ 2542248?p_p_id=101_INSTANCE_cKNonkJE02Bw\&_101_INSTANCE_cKNonkJE02 Bw_languageId=en_GB (accessed on 01.02.2019).

The Sustainable Development Goals Report. 2017. Accessed: 02.01.2019. URL: https://unstats.un.org/sdgs/files/report/2017/TheSustainableDevelopmentGoalsReport20 17_Russian.pdf.

The Advancing Freedom and Democracy Report. 2017. Accessed: 02.01.2019. URL: https://www.state.gov/j/drl/rls/afdr/index.htm.

Xi Jinping's report at the $19^{\text {th }}$ CPC National Congress. 2017. Accessed: 02.01.2019. URL: http://www.xinhuanet.com/english/download/Xi_Jinping's_report_at_19th_CPC_Nation al_Congress.pdf.

Viereck, G. S. 1929. What Life Means to Einstein: An Interview by George Sylvester Viereck. The Saturday Evening Post. October 26. 